\title{
Use of zeolites for macronutrients removal from wastewater
}

\author{
Barbora Urminská, Ján Derco, \\ Ronald Zakhar, Adriana Korpicsová \\ Institute of Chemical and Environmental Engineering, Department of Environmental Engineering, \\ Faculty of Chemical and Food Technology, Slovak University of Technology, \\ Radlinského 9, Bratislava, 812 37, Slovakia \\ b.urminska@gmail.com
}

\begin{abstract}
Natural or synthetic zeolites have unique physical, chemical and structural properties that predetermine their use in many processes, including wastewater treatment. This study presents the results of our preliminary research in the field of nitrogen and phosphorus removal using adsorption and adsorptive ozonation with natural and modified zeolites. Iron-modified zeolite was the most efficient for the removal of ammonium nitrogen by adsorption. Phosphorus removal efficiency using adsorption was relatively low and natural zeolite was not suitable for the phosphorus removal at all. Ozone had no significant impact on the removal efficiency. Regeneration of loaded zeolites with ozone has also been studied. This method was partly efficient but it needs be further examined.
\end{abstract}

Keywords: adsorption, nitrogen and phosphorus removal, wastewater treatment, zeolites

\section{Introduction}

Wastewater contains various pollutants of diverse chemical nature. Wastewater treatment techniques have progressed over the past decades. One of the possibilities is to use adsorbent materials, either for adsorption alone or in combination with other technologies.

Activated carbon, biomaterials, zeolites, clays and some industrial solid wastes are widely used for adsorption of ions and organic matter in wastewater. Natural or synthetic zeolites have unique physical, chemical and structural properties that predetermine their use in many processes. Properties of zeolites can be further improved by chemical treatment. Modified zeolites can also be used as catalysts in catalytic ozonation (Fontanier et al., 2006; Valdés and Zaror, 2006; Qu et al., 2007, Wang et al., 2011) as well as in combined processes, e.g., adsorptive ozonation (Fujita et al., 2004).

By altering the reaction conditions, the surface of zeolites or their internal structure can be changed (Földesová and Hudec, 2006). Zeolites have a porous structure and they are able to adsorb various sorbates, for example, pesticides, polar and nonpolar inorganic and organic molecules. Natural clinoptilolite has a high affinity to the $\mathrm{NH}_{4}{ }^{+}$cation and toxic metal cations; therefore, it can be used for their removal from wastewater (Reháková et al., 2003).

Nitrogen and phosphorus are essential macronutrients for all living forms. On the other hand, they are also significant pollutants due to their high content, particularly in municipal wastewater. Release of these macronutrients into receiving water has to be minimized due to their negative impact on aquatic environment and their removal is an essential part of the prevention of eutrophication problems. Specific production of nitrogen varies according to household equipment; it is approximately $12 \mathrm{~g}$ per person per day. Other significant sources of nitrogen are also animal wastes from agriculture, fertilizers, and the food industry (Pitter, 2015). Anthropogenic sources of inorganic phosphorus are washing and cleaning powders, degreasing and washing agents, as well as fertilizers. Animal waste contains phosphorus of both organic and inorganic origin. Specific phosphorus production is approximately $2-3 \mathrm{~g}$ per person per day (Pitter, 2015). Nitrogen and phosphorus can be efficiently removed from wastewaters by biological treatment which is commonly used at many wastewater treatment plants. Adsorption is one of the alternative methods that can be used when it is not possible to use activated sludge process, or in case it is necessary to include a tertiary treatment. The main advantage is that the adsorbents can also retain persistent pollutants that would otherwise only pass through the activated sludge bioreactor.

Ozonation is a perspective oxidation technology used for water and wastewater treatment. Adsorptive ozonation combines the benefits of both processes - ozonation and adsorption. Ozone has the ability to cleave organic molecules into smaller ones which then bind to the adsorbent. Adsorption also leads to a local increase in the concentration of pollutants and ozone at the adsorbent-liquid interface, which can contribute to increased pro- 
cess efficiency (Tsai et al., 2005; Melicher, 2013). Some adsorption materials (e.g., activated carbon, zeolites) may also serve as catalysts for the decomposition of ozone to hydroxyl radicals. Thus, the mechanism of direct ozone reactions, i.e., the mechanism of ozonolysis is changed to a radical reaction mechanism, which can lead to an increase in the efficiency of ozone reactions. Ruffino and Zanetti (2011; 2012) applied bromide as a catalyst for ammonia, bicarbonate and organic carbon depletion in ozonized systems.

Another combined process using ozone is the adsorption-regeneration process. Ishii et al. (1979) patented the ozonation method for regenerating an oxidation catalyst. Ozone can be used for the regeneration of loaded zeolites after the adsorption (Zhang et al., 2014). The authors successfully applied this process for adsorption of trichlorophenol on zeolite and adsorption regeneration with ozone. The adsorption capacity was kept stable for at least eight cycles of adsorption and regeneration. Fe-active zeolites were successfully applied in two cycles of the adsorption/oxidation approach of adsorption/wet peroxide oxidation of the non-ionic surfactant TX-100 (Shahbazi at al., 2014).

This study presents the results of our preliminary research in the field of wastewater treatment in adsorption and adsorptive ozonation processes for nitrogen and phosphorus removal. Natural zeolites, iron and manganese modified zeolites were used as adsorbents. Another aim of the research was to assess the possibilities of ozone regeneration of zeolites after adsorption applied for municipal wastewater treatment. These single and combined processes can be potentially applied in the treatment of sludge liquids and tertiary treatment of wastewater.

\section{Theoretical}

Adsorption can be defined as a process in which material (adsorbate) travels from a gas or liquid phase and forms a surface layer on a solid or liquid phase (Crawford and Quinn, 2017). The most common models describing the adsorption process kinetics are pseudo-first (Eq. 1) and pseudo-second (Eq. 2) order kinetics (Lin and Wang, 2009; Simonin, 2016, Naushad et al., 2016; Tan and Hameed, 2017). The pseudo-first order kinetic equation, originally described by Lagergren, assumes that the adsorption sites occupancy rate is proportional to the number of vacant sites. If film diffusion is the rate controlling process, the constant of the equation will vary inversely with the particle size and the film thickness (Ho and McKay, 1999).

\section{Pseudo-first order kinetic model}

$$
q_{t}=q_{e}\left(1-e^{-k_{1} t}\right)
$$

where $q_{\mathrm{t}}, q_{\mathrm{e}}$ express the quantity of adsorbate retained by the unit amount of adsorbent (adsorption capacity) at time $t$ and at equilibrium, respectively $\left[\mathrm{mg} \mathrm{g}^{-1}\right], k_{1}$ is the pseudo-first order rate constant $\left[\mathrm{min}^{-1}\right]$.

The pseudo-second order kinetic model is based on the assumption that the adsorption sites occupancy rate is proportional to the square of vacant sites. This model assumes that the overall sorption rate is controlled by the rate of adsorbate diffusion within the sorbent pores (Plazinski et al., 2013). Both these models were used in this study for the adsorption kinetics evaluation with model and municipal wastewater.

\section{Pseudo-second order kinetic model}

$$
q_{t}=q_{e} \frac{k_{2} q_{e} t}{1+k_{2} q_{e} t}
$$

where $q_{\mathrm{t}}, q_{\mathrm{e}}$ express the quantity of adsorbate retained by the unit amount of adsorbent (adsorption capacity) at time $t$ and at equilibrium, respectively $\left[\mathrm{mg} \mathrm{g}^{-1}\right], k_{2}$ is the pseudo-second-order rate constant $\left[\mathrm{g} \mathrm{mg}^{-1} \mathrm{~min}^{-1}\right]$.

Mass transfer during the adsorption process can also be controlled by external and internal diffusion (intra-particle diffusion). When the adsorbate diffusion in adsorbent pores is the adsorption rate-determining step, the intra-particle diffusion rate constant can be obtained from the Weber and Morris equation (Nagy et al., 2013; Li et al., 2016)

$$
q_{t}=\mathrm{k}_{\mathrm{ip}} t^{0.5}
$$

where $q_{\mathrm{t}}$ is the quantity of adsorbate retained by the unit amount of adsorbent $\left[\mathrm{mg} \mathrm{g}^{-1}\right]$ at time $t$ [min], $\mathrm{k}_{\mathrm{ip}}$ is the intra-particle diffusion rate constant $\left[\mathrm{mg} \mathrm{g}^{-1} \mathrm{~min}^{-0.5}\right]$ and $\mathrm{C}$ represents the boundarylayer effect. When external diffusion is the rate determining step, the liquid film diffusion model can be used (Nagy et al., 2013):

$$
\ln (1-\mathrm{F})=\mathrm{k}_{\mathrm{fd}} t
$$

where $F=q_{\mathrm{t}} / q_{\mathrm{c}}$ is the fraction attainment at equilibrium, and $k_{\mathrm{fd}}$ is the liquid film diffusion rate constant $\left[\mathrm{L} \mathrm{min}^{-1}\right]$.

The adsorption isotherm is a dependence of the quantity of the adsorbate adsorbed by the adsorbent (adsorption capacity) on pressure or adsorbate concentration under equilibrium conditions at constant temperature (Bleam, 2017). The most commonly used isotherms are Langmuir (Eq. 5) and Freundlich (Eq. 6) isotherms. The Langmuir isotherm is commonly used to describe 
the adsorption process on a homogeneous surface with negligible interactions between the adsorbed molecules. The model assumes uniform adsorption energy on the surface, and the maximum quantity of adsorbate depends on the level of the monolayer saturation. The Freundlich isotherm is known as an empirical, two-parameter, equation describing the adsorption process equilibrium. Unlike the Langmuir isotherm, Freundlich's model has no apparent adsorption maximum (Bleam, 2017). It can be applied to non-ideal and reversible adsorption, useful for heterogeneous surfaces as well as for multi-layer sorption.

\section{Langmuir isotherm}

$$
q=\frac{q_{\max } b C}{1+b C}
$$

where $q$ is the adsorption capacity $\left[\mathrm{mg} \mathrm{g}^{-1}\right], q_{\max }$ represents the maximum monolayer adsorption capacity $\left[\mathrm{mg} \mathrm{g}^{-1}\right], C$ is the equilibrium concentration of adsorbate $\left[\mathrm{mg} \mathrm{L}^{-1}\right]$, and $b$ is the equilibrium constant of interaction $\left[\mathrm{L} \mathrm{mg}^{-1}\right]$.

\section{Freundlich isotherm}

$$
q=k C^{\frac{1}{n}}
$$

where $q$ is the adsorption capacity of adsorbate $\left[\mathrm{mg} \mathrm{g}^{-1}\right], C$ is the equilibrium concentration of adsorbate $\left[\mathrm{g} \mathrm{L}^{-1}\right]$, and $k$ and $n$ are empirical constants $\left[\mathrm{mg}^{(1-1 / n)} \mathrm{g}^{-1} \mathrm{~L}^{1 / n}\right],[-]$ (Bowman, 1982).

Critical properties of the Langmuir isotherm can also be affirmed from the viewpoint of equilibrium parameter $\left(R_{\mathrm{L}}\right.$, also called the separation factor), a dimensionless constant defined by Eq. 7. The value of $R_{\mathrm{L}}$ indicates the shape of the isotherms to be either unfavorable $\left(R_{\mathrm{L}}>1\right)$, linear $\left(R_{\mathrm{L}}=1\right)$, favorable $\left(0<R_{\mathrm{L}}<1\right)$ or irreversible $\left(R_{\mathrm{L}} \approx 0\right)$ (Das et al., 2014; Foo and Hameed, 2010; Nethaji et al., 2013).

$$
R_{L}=\frac{1}{1+b C_{0}}
$$

The Freundlich empirical constant $1 / n$ as a function of the adsorption strength in the adsorption process was also considered. The value of $1 / n$ in the range from zero to one also indicates a favorable sorption process (Das et al., 2014; Nethaji et al., 2013).

\section{Materials and methods}

\section{Adsorption and adsorptive ozonation}

Glass laboratory reactors with a volume of $1 \mathrm{~L}$ stirred by a magnetic stirrer were used in all adsorption experiments. Model wastewater was prepared from deionized water and $\mathrm{NH}_{4} \mathrm{OH}$, so the concen- tration of ammonium nitrogen corresponded to the content in municipal wastewater (approximately $70 \mathrm{mg} \mathrm{L}^{-1}$ ). Municipal wastewater was sampled from the municipal wastewater treatment plant in Bratislava-Vrakuña. Natural zeolite with the fraction size of over $1 \mathrm{~mm}$, two zeolites modified by manganese (fraction size $0.3-2.5 \mathrm{~mm}$ and $1-2.5 \mathrm{~mm}$ ) and one modified by iron (fraction size $1-2.5 \mathrm{~mm}$ ) were used for the experiments. The zeolites were supplied by Zeocem, Slovakia. The adsorbent amount was $20 \mathrm{~g}$ per $1 \mathrm{~L}$ of water. The experiments were carried out at laboratory temperature of $20 \pm 2{ }^{\circ} \mathrm{C}$ with the main aim to evaluate and asses the adsorption potential of natural and modified zeolites for nitrogen and phosphorus removal. Another goal was to determine the adsorption equilibrium time, describe the adsorption kinetics and determine the values of parameters of adsorption isotherms for the evaluation of adsorption potential of the investigated zeolite samples.

A Lifetech ozone generator with a maximum ozone production of $5 \mathrm{~g} \mathrm{~L}^{-1}$ was used for ozone production from pure oxygen. Ozone concentration in the gas phase at the inlet and outlet of the reactor was measured using a Lifetech ODU 200 UV laboratory detector. The system was operated in a batch configuration: wastewater samples and adsorbents were added to the reactor at the start of each experiment. The mixture of ozone and oxygen was fed into the reactor through a glass frit to form fine bubbles and thus to increase the efficiency of ozone transfer to the liquid phase. A magnetic stirrer was used to stir the reaction mixture. During the ozonation, the ozone generator power was set to $50 \%$ and the oxygen flow was maintained at $1 \mathrm{~L} \mathrm{~min}^{-1}$. Municipal wastewater was used in the experiments. The amount of adsorbent was $20 \mathrm{~g}$ per 1 liter of wastewater. Ozonation without any sorbent was also performed. Ozonation time was $60 \mathrm{~min}$.

Repeated adsorption was carried out with municipal wastewater to investigate the adsorption-regeneration process with the ozone regeneration of zeolites. For each zeolite, five cycles of adsorption ( $2 \mathrm{~h}, 20 \mathrm{~g}$ of zeolite, $1 \mathrm{~L}$ of wastewater) were performed and followed by $15 \mathrm{~min}$ ozone regeneration using the reactor and conditions described above.

\section{Analytical methods}

Ammonium nitrogen concentrations were determined using the absorption spectrophotometric method with the Nessler reagent. In a test tube, $5 \mathrm{~mL}$ of the sample was mixed with 1-2 drops of a potassium-sodium tartrate solution $\left(500 \mathrm{~g} \mathrm{~L}^{-1}\right)$ and $100 \mu \mathrm{L}$ of the Nessler's reagent $\left(10 \mathrm{~g}\right.$ of $\mathrm{HgI}_{2}$ and $7 \mathrm{~g}$ of $\mathrm{KI}$ in $100 \mathrm{~mL}$ of $10 \% \mathrm{NaOH})$. A yellow-brown colloidal complex was formed. The color intensity 
was measured after $10 \mathrm{~min}$ by a spectrophotometer at the wavelength of $425 \mathrm{~nm}$ (Horáková et al., 2003). Phosphate phosphorus concentrations were also measured spectrophotometrically. Five $\mathrm{mL}$ of the sample were mixed in a test tube with $0.5 \mathrm{~mL}$ of the agent solution prepared by mixing $125 \mathrm{~mL}$ of sulfuric acid $\left(2.5 \mathrm{~mol} \mathrm{~L}^{-1}\right), 50 \mathrm{~mL}$ of ammonium molybdate solution $\left(30 \mathrm{~g} \mathrm{~L}^{-1}\right), 25 \mathrm{~mL}$ of antimonypotassium tartrate solution $\left(1.36 \mathrm{~g} \mathrm{~L}^{-1}\right)$ and $50 \mathrm{~mL}$ of ascorbic acid solution $\left(21.6 \mathrm{~g} \mathrm{~L}^{-1}\right)$. After 15 minutes, the absorbance was measured by a spectrophotometer at $690 \mathrm{~nm}$ (Horáková et al., 2003).

Values of COD and TOC were determined by the National Water Reference Laboratory, Water Research Institute in Bratislava.

\section{Experimental data processing}

Nonlinear regression was used for data analysis and fitting the values in the models. Parameter values of Eqs. 1, 2, 5 and 6 were determined by the grid search optimization procedure. The values of correlation coefficient and residual sum of squares between the measured and calculated data were used to compare the adsorption potential of the investigated zeolites and to evaluate the quality of the mathematical description of the experimental data. We strongly support the conclusion of authors Lin and Wang (2009) that nonlinear form of kinetic equations should be primarily used to obtain kinetic parameters. The reason is that linearization can distort the basic assumption of the least square method, i.e., constant Gaussian distribution of values of the dependent variable for all values of the independent variable.

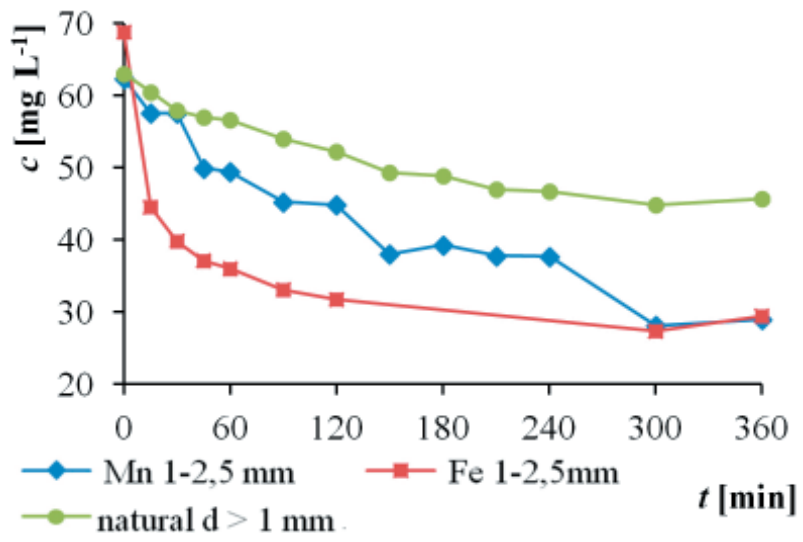

Fig. 1. Time dependence of ammonium nitrogen concentration in model wastewater.

\section{Results and discussion}

\section{Adsorption with model wastewater}

The first set of experiments was carried out with model wastewater containing ammonium nitrogen as the only pollutant. Fig. 1 shows that the equilibrium time in the adsorption with model wastewater was about $300 \mathrm{~min}$. However, most of the ammonium nitrogen was adsorbed in the first two hours. This time was therefore used for the measurements of equilibrium data and determination of adsorption isotherm parameters. Unmodified zeolite (in Fig. 1 marked as "natural $\mathrm{d}>1 \mathrm{~mm}$ ") performed the lowest decrease of $\mathrm{N}-\mathrm{NH}_{4}$. The best results were obtained using Fe-modified zeolite (in Fig. 1 marked as Fe 1-2,5 mm). The pseudo-first and pseudo-second order kinetic parameters are shown in Tables 1 and 2.

Tab. 1. Parameter values of pseudo-first order kinetics and statistical characteristics for $\mathrm{N}_{-} \mathrm{NH}_{4}$ adsorption from model wastewater $\left(S_{\mathrm{R}}{ }^{2}-\right.$ residual sum of squares of experimental and calculated values; $S_{\mathrm{Y}}{ }^{2}-$ dispersion of dependent variable values; $R_{\mathrm{xy}}-$ correlation coefficient).

\begin{tabular}{lccccc}
\hline Zeolite & $\begin{array}{c}\boldsymbol{q}_{\mathrm{e}} \\
{\left[\mathbf{m g ~ g}^{-1}\right]}\end{array}$ & $\begin{array}{c}\boldsymbol{k}_{\mathbf{1}} \\
{\left[\mathbf{m i n}{ }^{1}\right]}\end{array}$ & $\begin{array}{c}\boldsymbol{S}_{\mathrm{R}}{ }^{2} \\
{\left[\mathbf{m g}^{2} \mathbf{g}^{-2}\right]}\end{array}$ & $\begin{array}{c}S_{\mathrm{Y}}{ }^{2} \\
{\left[\mathbf{m g}^{2} \mathbf{g}^{-2}\right]}\end{array}$ & $\begin{array}{c}\boldsymbol{R}_{\mathrm{xy}} \\
{[-]}\end{array}$ \\
\hline Natural & 0.980 & 0.00750 & 0.00154 & 0.0910 & 0.989 \\
Fe-modified & 1.80 & 0.0698 & 0.0142 & 0.389 & 0.964 \\
Mn-modified & 1.28 & 0.0170 & 0.00150 & 0.180 & 0.991 \\
\hline
\end{tabular}

Tab. 2. Parameter values of pseudo-second order kinetics and statistical characteristics for $\mathrm{N}-\mathrm{NH}_{4}$ adsorption from model wastewater $\left(S_{\mathrm{R}}{ }^{2}-\right.$ residual sum of squares of experimental and calculated values; $S_{\mathrm{Y}}{ }^{2}-$ dispersion of dependent variable values; $R_{\mathrm{xy}}-$ correlation coefficient).

\begin{tabular}{|c|c|c|c|c|c|}
\hline Zeolite & $\begin{array}{c}q_{\mathrm{e}} \\
{\left[\mathrm{mg} \mathrm{g}^{-1}\right]}\end{array}$ & $\begin{array}{c}k_{2} \\
{\left[\mathrm{~g} \mathrm{mg}^{1}{ }^{1} \min { }^{1}\right]}\end{array}$ & $\begin{array}{c}S_{\mathrm{R}}{ }^{2} \\
{\left[\mathrm{mg}^{2} \mathbf{g}^{-2}\right]}\end{array}$ & $\begin{array}{c}S_{\mathrm{Y}}^{2} \\
{\left[\mathrm{mg}^{2} \mathbf{g}^{-2}\right]}\end{array}$ & $\begin{array}{l}R_{\mathrm{xy}} \\
{[-]}\end{array}$ \\
\hline Natural & 0.860 & 0.0208 & 0.0100 & 0.0910 & 0.890 \\
\hline Fe-modified & 1.92 & 0.0592 & 0.00720 & 0.389 & 0.982 \\
\hline Mn-modified & 1.42 & 0.0172 & 0.00460 & 0.180 & 0.974 \\
\hline
\end{tabular}


The pseudo-first order model corresponded with the experimental values obtained with the Mnmodified zeolite and the natural zeolite better than the pseudo-second order one. The pseudo-second order model had a slightly higher correlation coefficient in case of Fe-modified zeolite but the difference was negligible. The highest rate constants were obtained for Fe-modified zeolite according to both kinetic models.

Results of the experiments aiming to determine the parameters of adsorption isotherms and provide an insight on adsorption mechanisms with model wastewater are summarized in Table 3 and Fig. 2. Comparison of the values of correlation coefficients indicates that the Langmuir isotherm better corresponded with the experimental data than the Freundlich isotherm. The Fe-modified zeolite was again the most efficient, i.e., the highest adsorption quantities were reached; while natural zeolite was the least efficient adsorbent. The calculated values of equilibrium parameter $R_{\mathrm{L}}(\mathrm{Eq}$. 7) were in the range from 0.17 to 0.62 for natural zeolite, from 0.16 to 0.65 for Mn-modified zeolite and from 0.18 to 0.71 for Fe-modified zeolite, depending on the initial concentration values. It can be concluded that for all investigated zeolites, the values of equilibrium parameter were $<1$ and $>0$ for all initial ammonium nitrogen concentrations, which indicates favorable adsorption. Values of the Freundlich empirical constant $1 / n$ also lie between 0 and 1 for all types of zeolites, which also indicates favorable sorption process.

According to Eq. 3 and data shown in Fig. 1, linear plot of the equation passes through the origin in case of natural $\left(R_{\mathrm{xy}}=0.986\right)$ and Mn-modified zeolite $\left(R_{\mathrm{xy}}=0.981\right)$. Based on the values of the correlation coefficient $\left(R_{\mathrm{xy}}\right)$, it can be concluded that for these two zeolites, internal diffusion is the rate determining step. This is not the case of Fe-modified zeolite $\left(R_{\mathrm{xy}}=0.820\right)$. According to Eq. 4 and data shown in Fig. 1, linear plot of the equation passes through the origin in case of natural zeolite $\left(R_{\mathrm{xy}}=0.978\right)$ and Mn-modified zeolite $\left(R_{\mathrm{xy}}=0.956\right)$. It can be concluded that for these two zeolites, kinetics of the adsorption process was controlled by diffusion through the liquid film surrounding the adsorbent. In case of Fe-modified zeolite, the value of the correlation coefficient was lower, 0.904 .

\section{Adsorption with municipal wastewater}

Fig. 3 shows the decrease in ammonium nitrogen concentration for unmodified zeolite (natural $\mathrm{d}>1 \mathrm{~mm}$ ) and modified zeolites with manganese and iron ( $\mathrm{Mn} 1-2.5 \mathrm{~mm}$ and $\mathrm{Fe} 1-2.5 \mathrm{~mm}$ ). Unmodified zeolite showed the lowest efficiency while the highest efficiency was again achieved by the Fe-modified zeolite. Equilibrium time for natural and Fe-modified zeolite was around

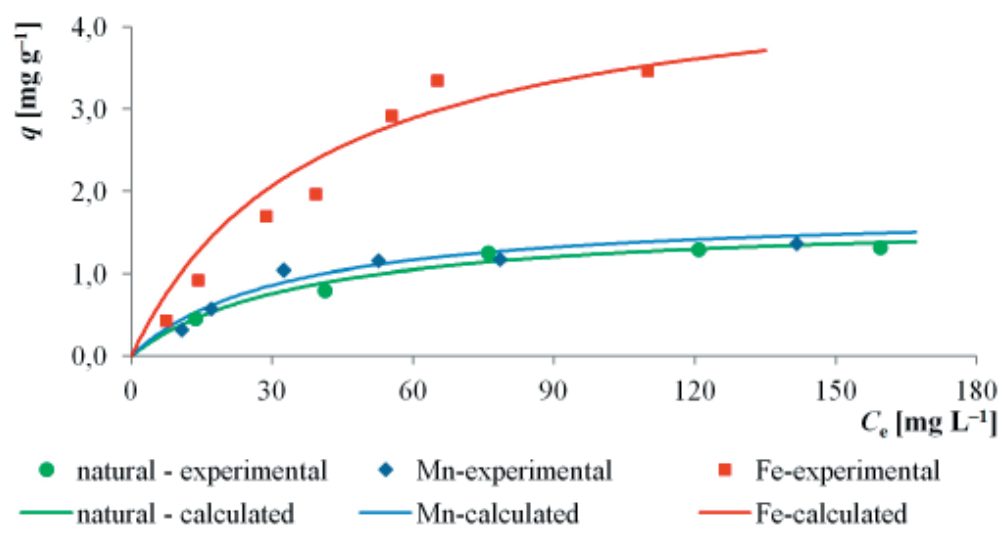

Fig. 2. Experimental values of adsorption capacities dependence on equilibrium concentration of ammonium nitrogen adsorption from model wastewater and calculated values using Langmuir isotherm.

Tab. 3. Adsorption isotherm parameters and correlation coefficients $\left(R_{\mathrm{xy}}\right)$ for $\mathrm{N}-\mathrm{NH}_{4}$ adsorption from model wastewater obtained by nonlinear regression.

\begin{tabular}{|c|c|c|c|c|c|c|}
\hline \multirow[b]{2}{*}{ Zeolite } & \multicolumn{3}{|c|}{ Langmuir isotherm } & \multicolumn{3}{|c|}{ Freundlich isotherm } \\
\hline & $\begin{array}{c}q_{\max } \\
{\left[\mathrm{mg} \mathrm{g}^{-1}\right]}\end{array}$ & $\begin{array}{c}b \\
{\left[\mathrm{~L} \mathrm{mg}^{-1}\right]}\end{array}$ & $\begin{array}{l}R_{\mathrm{xy}} \\
{[-]}\end{array}$ & $\begin{array}{c}k \\
{\left[\mathrm{mg}^{(1-1 / n)} \mathrm{g}^{-1} \mathrm{~L}^{1 / n}\right]}\end{array}$ & $\begin{array}{l}1 / n \\
{[-]}\end{array}$ & $\begin{array}{l}R_{\mathrm{xy}} \\
{[-]}\end{array}$ \\
\hline Natural & 1.69 & 0.0273 & 0.984 & 0.118 & 0.500 & 0.942 \\
\hline Fe-modified & 4.80 & 0.0252 & 0.942 & 0.247 & 0.547 & 0.980 \\
\hline Mn-modified & 1.79 & 0.0311 & 0.960 & 0.138 & 0.518 & 0.923 \\
\hline
\end{tabular}




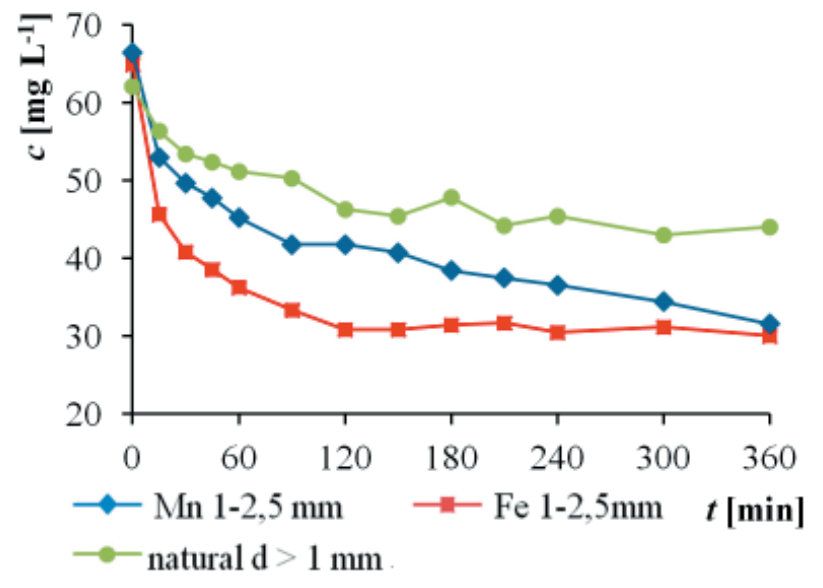

Fig. 3. Time dependence of ammonium nitrogen concentration in municipal wastewater.

$120 \mathrm{~min}$; in case of Mn-modified zeolite, the equilibrium was not reached even after $360 \mathrm{~min}$, but the majority of ammonium nitrogen was adsorbed within $120 \mathrm{~min}$.

The pseudo-first and pseudo-second order kinetic parameters for this process are shown in Tables 4 and 5. The equilibrium times and adsorption quantities were about the same as in the experiments with model water. The pseudo-first order model better corresponded with the experimental data for all three zeolites; the correlation coefficients were significantly higher compared to the pseudo-second order model. The highest rate constants were again obtained for the Fe-modified zeolite.

Results of the adsorption isotherm parameters determination and insight on the adsorption mechanisms with municipal wastewater are summarized in Tables 6 and Fig. 4. Comparison of the correla- tion coefficient values indicates that the Langmuir isotherm described the experiment more accurately than the Freundlich one. Again, Fe-modified zeolite exhibited the highest ammonium nitrogen removal capacity. The presence of other pollutants in wastewater did not seem to negatively influence the process of ammonium nitrogen adsorption; on the contrary, higher maximal quantities of adsorbate were reached for all three zeolites with municipal wastewater than with model wastewater.

The calculated values of equilibrium parameter $\left(R_{\mathrm{L}}\right)$ were more or less constant for all studied zeolites, i.e., 0.37 for natural zeolite, 0.47 for Mn-modified zeolite and 0.55 for Fe-modified zeolite for all initial concentration values. Values of the equilibrium parameter were $<1$ and $>0$ for all investigated zeolites and all initial ammonium nitrogen concentrations, which indicates favorable adsorption. Values of the Freundlich empirical constant $(1 / n)$ for all types of zeolite are also in the interval of 0 to 1 , which again indicates favorable sorption process.

According to Eq. 3 and data given in Fig. 3, linear plot of the equation passes through the origin in case of natural zeolite $\left(R_{\mathrm{xy}}=0.916\right)$. Based on the value of correlation coefficient $R_{\mathrm{xy}}$ it can be concluded that for this zeolite, internal diffusion is the rate determining step. This is not the case of $\mathrm{Mn}$ modified zeolite $\left(R_{\mathrm{xy}}=0.854\right)$ and Fe-modified zeolite $\left(R_{\mathrm{xy}}=0.756\right)$ According to Eq. 4 and data shown in Fig. 3, linear plot of the equation passes through the origin in case of natural zeolite $\left(R_{\mathrm{xy}}=0.930\right)$ and Mn-modified zeolite $\left(R_{\mathrm{xy}}=0.909\right)$. It can be concluded that for these two zeolites, kinetics of the adsorption process is also controlled by diffusion through the liquid film surrounding the adsorbent.

Tab. 4. Parameters of pseudo-first order kinetics and statistical characteristics for $\mathrm{N}_{-} \mathrm{NH}_{4}$ adsorption from municipal wastewater $\left(S_{\mathrm{R}}{ }^{2}-\right.$ residual sum of squares of experimental and calculated data; $S_{\mathrm{Y}}{ }^{2}-$ dispersion of dependent variable values; $R_{\mathrm{xy}}-$ correlation coefficient).

\begin{tabular}{lccccc}
\hline Zeolite & $\begin{array}{c}\boldsymbol{q}_{\mathrm{e}} \\
{\left[\mathbf{m g ~ g}^{-1}\right]}\end{array}$ & $\begin{array}{c}\boldsymbol{k}_{\mathbf{1}} \\
{\left[\mathbf{m i n}{ }^{1}\right]}\end{array}$ & $\begin{array}{c}\boldsymbol{S}_{\mathrm{R}}{ }^{2} \\
{\left[\mathbf{m g}^{2} \mathbf{g}^{-2}\right]}\end{array}$ & $\begin{array}{c}\boldsymbol{S}_{\mathrm{Y}}{ }^{2} \\
{\left[\mathbf{m g}^{2} \mathbf{g}^{-2}\right]}\end{array}$ & $\begin{array}{c}\boldsymbol{R}_{\mathrm{xy}} \\
{[-]}\end{array}$ \\
\hline Natural & 0.874 & 0.0174 & 0.00428 & 0.0790 & 0.946 \\
Fe-modified & 1.68 & 0.0425 & 0.00563 & 0.238 & 0.976 \\
Mn-modified & 1.49 & 0.0228 & 0.0173 & 0.213 & 0.919 \\
\hline
\end{tabular}

Tab. 5. Parameters of pseudo-second order kinetics and statistical characteristics for $\mathrm{N}-\mathrm{NH}_{4}$ adsorption from municipal wastewater $\left(S_{\mathrm{R}}{ }^{2}-\right.$ residual sum of squares of experimental and calculated data; $S_{\mathrm{Y}}{ }^{2}-$ dispersion of dependent variable values; $R_{\mathrm{xy}}-$ correlation coefficient).

\begin{tabular}{lccccc}
\hline Zeolite & $\begin{array}{c}\boldsymbol{q}_{\mathrm{e}} \\
{\left[\mathrm{mg} \mathrm{g}^{-1}\right]}\end{array}$ & $\begin{array}{c}\boldsymbol{k}_{\mathbf{2}} \\
{\left[\mathrm{g} \mathrm{mg}^{1} \mathbf{m i n}\right.}\end{array}$ & $\begin{array}{c}\boldsymbol{S}_{\mathrm{R}}{ }^{2} \\
{\left[\mathbf{m g}^{2} \mathbf{g}^{-2}\right]}\end{array}$ & $\begin{array}{c}\boldsymbol{S}_{\mathrm{Y}}{ }^{2} \\
{\left[\mathbf{m g}^{2} \mathbf{~}^{-2}\right]}\end{array}$ & $\begin{array}{c}\boldsymbol{R}_{\mathrm{xy}} \\
{[-]}\end{array}$ \\
\hline Natural & 0.86 & 0.0450 & 0.00742 & 0.079 & 0.906 \\
Fe-modified & 1.70 & 0.0581 & 0.00617 & 0.238 & 0.974 \\
Mn-modified & 1.39 & 0.0485 & 0.0277 & 0.213 & 0.870 \\
\hline
\end{tabular}




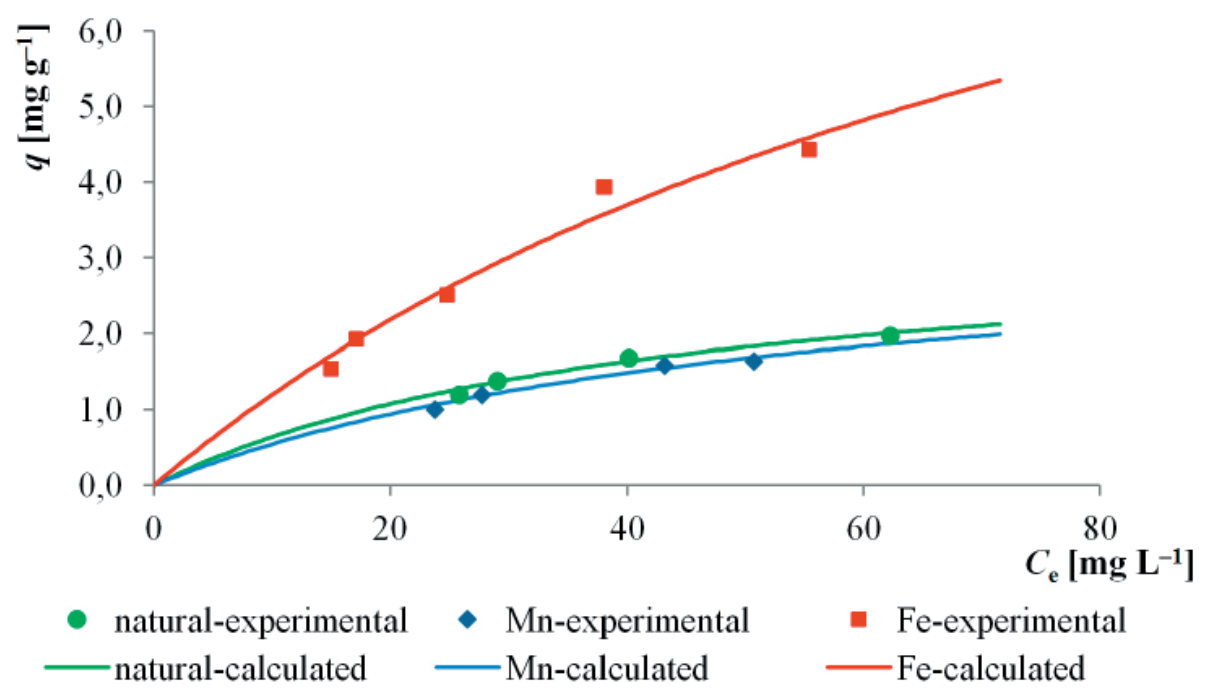

Fig. 4. Experimental values of adsorption capacities dependence on equilibrium concentration of ammonium nitrogen adsorption from municipal wastewater and calculated values using Langmuir isotherm.

Tab. 6. Adsorption isotherm parameter values and correlation coefficient values $\left(R_{\mathrm{xy}}\right)$ for $\mathrm{N}-\mathrm{NH}_{4}$ adsorption in municipal wastewater

\begin{tabular}{lcccccc}
\hline \multirow{2}{*}{ Zeolite } & \multicolumn{3}{c}{ Langmuir isotherm } & \multicolumn{3}{c}{ Freundlich isotherm } \\
\cline { 2 - 7 } & $\begin{array}{c}\boldsymbol{q}_{\max } \\
{\left[\mathbf{m g ~ g ~}^{-1}\right]}\end{array}$ & $\begin{array}{c}\boldsymbol{b} \\
{\left[\mathbf{L ~ m g}^{-1}\right]}\end{array}$ & $\begin{array}{c}\boldsymbol{R}_{\mathrm{xy}} \\
{[-]}\end{array}$ & $\begin{array}{c}\boldsymbol{k} \\
{\left[\mathbf{m g}^{(1-1 / n)} \mathbf{g}^{-1} \mathbf{L}^{\mathbf{1 / n}}\right]}\end{array}$ & $\begin{array}{c}\mathbf{1} \boldsymbol{n} \\
{[-]}\end{array}$ & $\begin{array}{c}\boldsymbol{R}_{\mathrm{xy}} \\
{[-]}\end{array}$ \\
\hline Natural & 3.40 & 0.0232 & 0.996 & 0.283 & 0.472 & 0.993 \\
Fe-modified & 12.2 & 0.0109 & 0.985 & 0.283 & 0.744 & 0.979 \\
Mn-modified & 3.49 & 0.0185 & 0.997 & 0.0760 & 0.803 & 0.981 \\
\hline
\end{tabular}

In case of Fe-modified zeolite, the correlation coefficient was lower, 0.574 .

The next series of experiments were performed with Mn-modified zeolite of the fraction size $0.3-2.5 \mathrm{~mm}$. Mn-modified zeolite with the fraction size $1.0-2.5 \mathrm{~mm}$ and iron modified zeolite of the same fraction size $(1.0-2.5 \mathrm{~mm})$ were also used. The decrease in concentrations of ammonium nitrogen

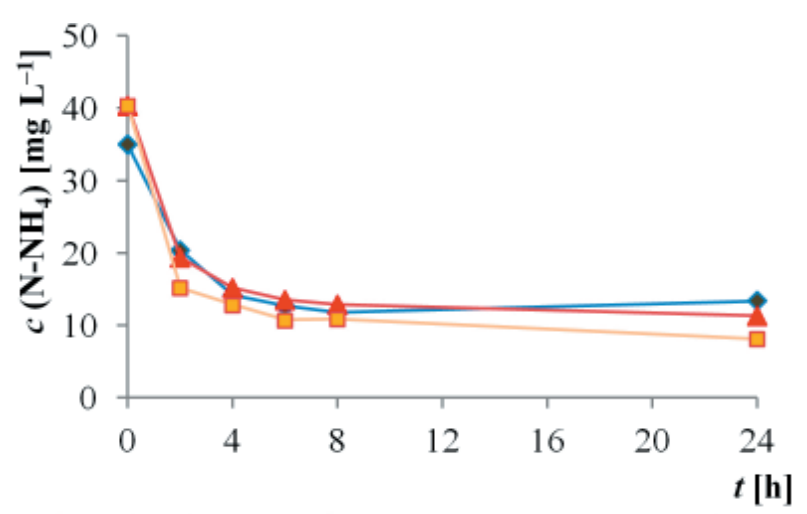

$\longrightarrow \operatorname{Mn~1,0-2,5-4n~0,3-2,5-\square -Fe~1,0~-~2,5~}$

Fig. 5. Time dependence of ammonium nitrogen concentration in municipal wastewater during adsorption on three types of modified zeolites.
$\left(\mathrm{N}-\mathrm{NH}_{4}\right)$, total nitrogen $\left(\mathrm{N}_{\text {tot }}\right)$, phosphate phosphorus $\left(\mathrm{P}^{-} \mathrm{PO}_{4}\right)$, chemical oxygen demand (COD) and total organic carbon (TOC) over time is shown in Figs. 5-9. All three zeolites showed similar rates of $\mathrm{N}-\mathrm{NH}_{4}, \mathrm{~N}_{\text {tot }}$, COD and TOC removal. However, for the removal of $\mathrm{P}_{-} \mathrm{PO}_{4}, \mathrm{Fe}-$ modified zeolite showed significantly lower efficiency than Mn-modified zeolites. Most pollution was eliminated in the first

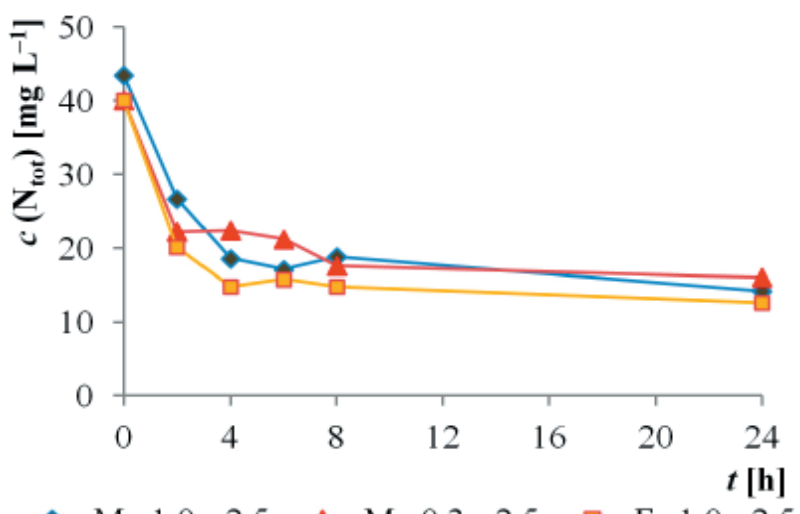

Fig. 6. Time dependence of total nitrogen concentration in municipal wastewater during adsorption on three types of modified zeolites. 


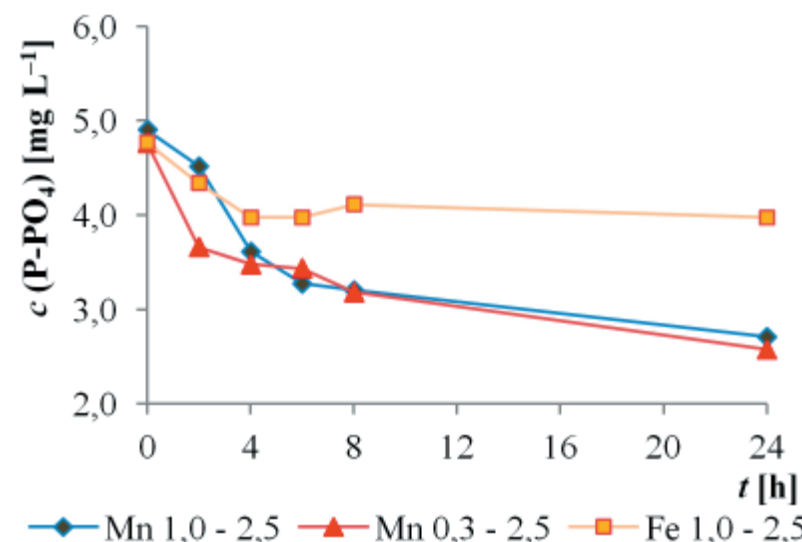

Fig. 7. Time dependence of phosphate phosphorus concentration in municipal wastewater during adsorption on three types of modified zeolites.

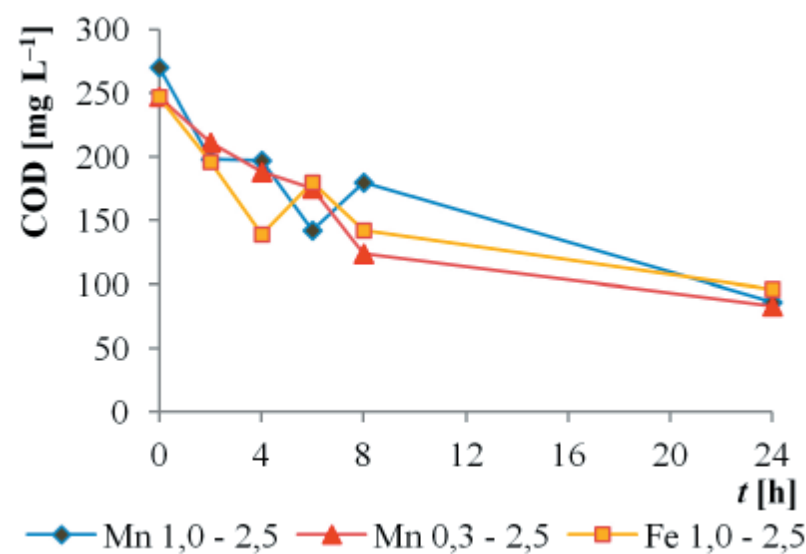

Fig. 8. Time dependence of chemical oxygen demand (COD) in municipal wastewater during adsorption on three types of modified zeolites.

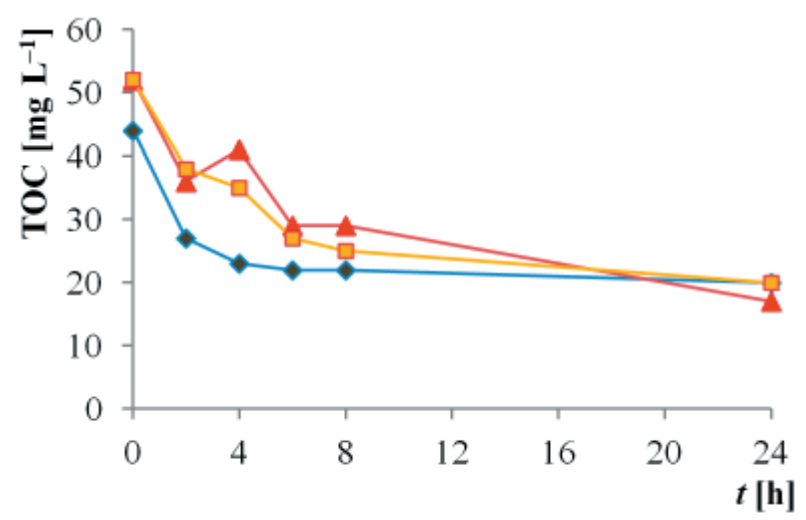

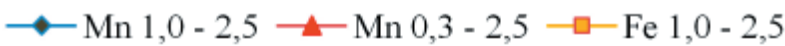

Fig. 9. Time dependence of total organic carbon concentration (TOC) in municipal wastewater during adsorption on three types of modified zeolites.

two hours of adsorption, but the equilibrium time was around six hours in most measurements. The fraction size of Mn-modified zeolite did not have a significant impact on the adsorption efficiency.

\section{Adsorptive ozonation}

Zeolites modified with $\mathrm{Mn}$ and $\mathrm{Fe}$ (fraction size $1.0-2.5 \mathrm{~mm}$ ) and natural zeolite (fraction size of over $1 \mathrm{~mm}$ ) were used in this part of the study. Fig. 10 shows the decreasing values of ammonium nitrogen concentrations during ozonation and adsorptive ozonation. Ozonation alone was the least efficient compared to adsorptive ozonation. The removal efficiency was only $5.7 \%$ while modified zeolites were more efficient. The highest efficiency was achieved with Fe-modified zeolite. However, the efficiency was approximately the same as after adsorption alone (without ozonation), so adsorptive ozonation was not efficient in this case. The efficiency of each zeolite also corresponds to the results obtained in the adsorption experiments, where Fe-modified zeolite was the most and natural zeolite was the least efficient.

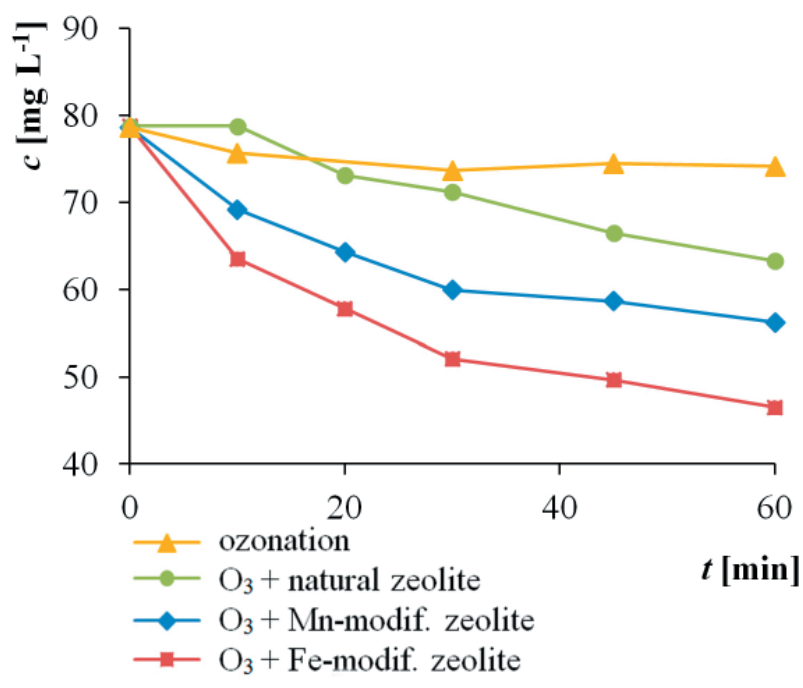

Fig. 10. Time dependence of $\mathrm{N}-\mathrm{NH}_{4}$ concentration during ozonation and adsorptive ozonation.

Fig. 11 shows COD concentrations during the ozonation and adsorptive ozonation processes. During ozonation, the highest COD decrease can be seen after ten minutes of the process. COD removal efficiency reached $15 \%$ after 60 minutes. For adsorptive ozonation, the highest decrease in COD was achieved by the Fe-modified zeolite (39\% decrease); the least efficient was the natural zeolite which removed $26.7 \%$ of COD from the effluent. The Mn-modified zeolite efficiency was about $33 \%$. In this case, the process of adsorptive ozonation seems to be more efficient than adsorption alone (Fig. 6) probably thanks to strong oxidizing properties of ozone which is capable of removing organic pollution expressed as COD. However, the difference is not very significant and using ozone is not feasible due to operation costs. 


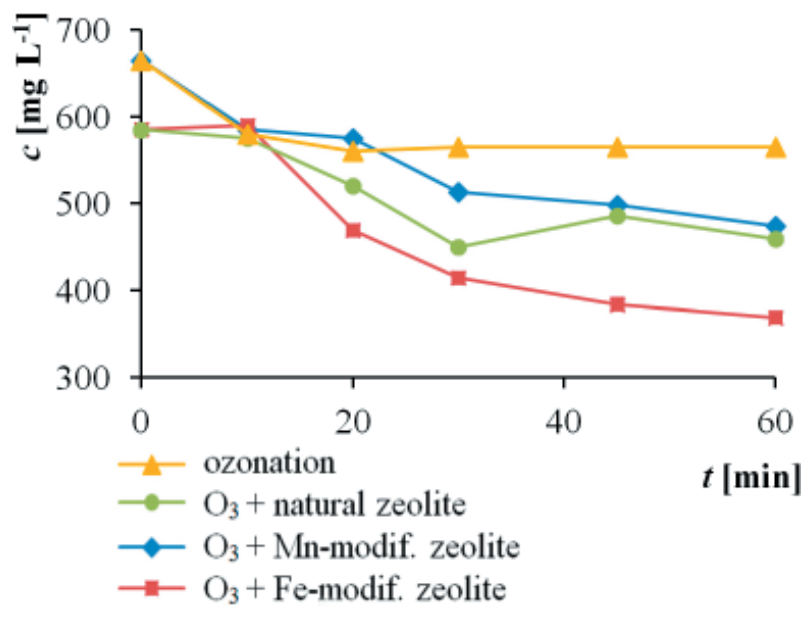

Fig. 11. Time dependence of COD concentration during ozonation and adsorptive ozonation.

\section{Regeneration of zeolites using ozone}

Fig. 12 shows the efficiency of ammonium nitrogen removal by repeated adsorption followed by regeneration. Decreasing tendency of the ammo- nium nitrogen removal efficiency for all types of zeolites is evident, which means that sorption capacity of the zeolites was not completely recovered. In Figs. 13-16, decrease in the concentrations of $\mathrm{N}-\mathrm{NH}_{4}, \mathrm{P}_{-} \mathrm{PO}_{4}, \mathrm{COD}$ and TOC during the adsorption are expressed in the positive direction of the $y$-axis while the amounts desorbed from the zeolite during regeneration are in the negative direction of the $y$-axis. The amounts of nitrogen released from the zeolites in four regeneration cycles ranged from $4.4 \mathrm{mg} \mathrm{L}^{-1}$ to $13.1 \mathrm{mg} \mathrm{L}^{-1}$ and the amounts of phosphorus ranged from $0.1 \mathrm{mg} \mathrm{L}^{-1}$ to $0.3 \mathrm{mg} \mathrm{L}^{-1}$. Residual concentrations of ammonium nitrogen and phosphate phosphorus in the liquid phase after the regeneration of individual zeolites with ozone are a little higher than those after the desorption without the presence of ozone (performed in a stirred reactor using deionized water), where only about $1 \mathrm{mg} \mathrm{L}^{-1}$ of ammonium nitrogen and less than $0.8 \mathrm{mg} \mathrm{L}^{-1}$ of phosphate phosphorus were desorbed in the same time.

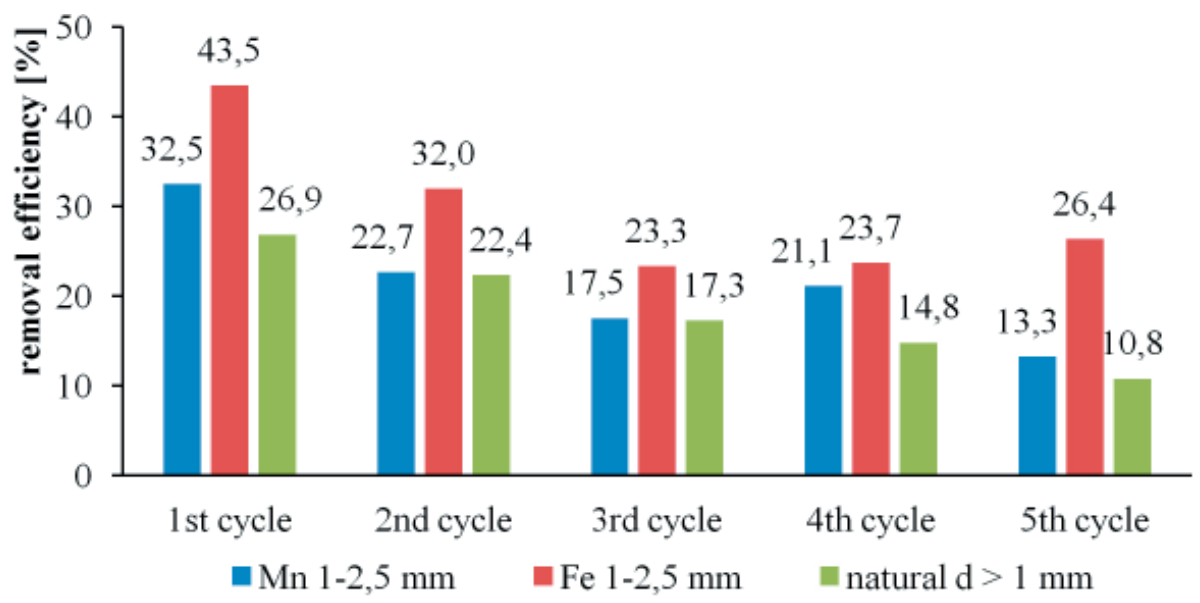

Fig. 12. Efficiency of $\mathrm{N}-\mathrm{NH}_{4}$ removal from real wastewater in five cycles of adsorption and regeneration with $\mathrm{O}_{3}$.

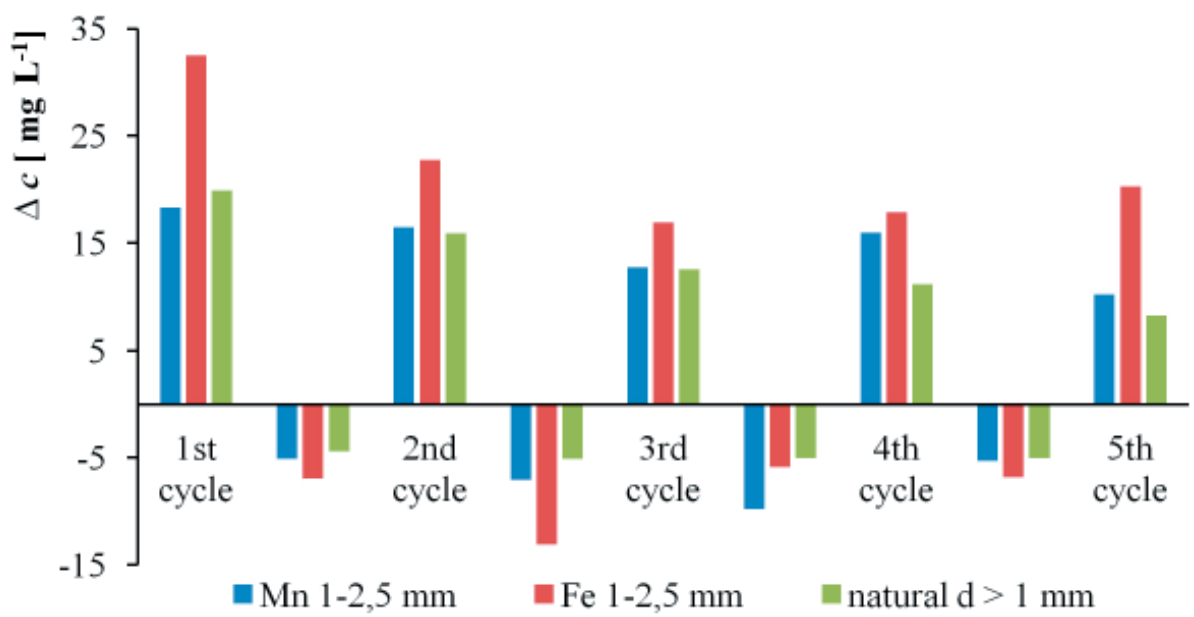

Fig. 13. Change of $\mathrm{N}^{-\mathrm{NH}_{4}}$ concentration in five cycles of adsorption followed by regeneration with $\mathrm{O}_{3}$. 
This suggests that regeneration by ozone takes place on the zeolites surface. The mechanism of adsorptive ozonation can be caused by increased amount of pollutants and ozone concentration on the surface of zeolites and the subsequent oxidation reactions. Another possible mechanism of regeneration is catalytic ozonation, which is accompanied by the formation of free hydroxyl radicals. In case of the studied zeolites, a combination of both mechanisms can be assumed. Another possible explanation is the recovery of free adsorption sites for ammonium nitrogen adsorption by oxidation of the adsorbed

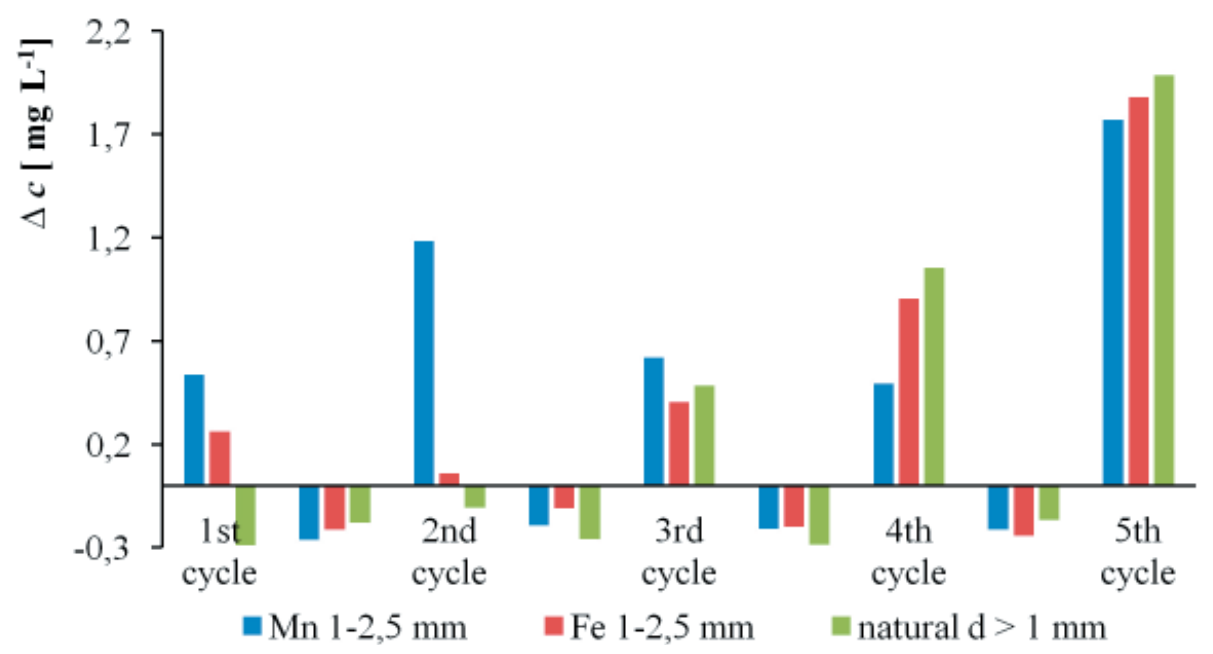

Fig. 14. Change of $\mathrm{P}_{-} \mathrm{PO}_{4}$ concentration in five cycles of adsorption followed by regeneration with $\mathrm{O}_{3}$.

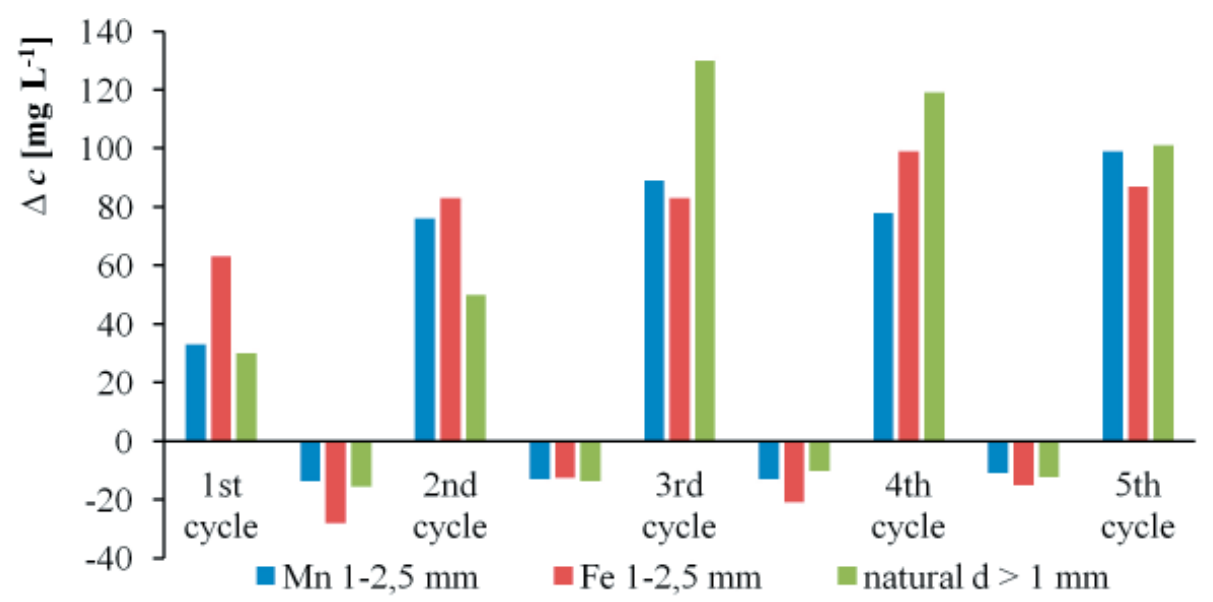

Fig. 15. Change of COD in five cycles of adsorption followed by regeneration with $\mathrm{O}_{3}$.

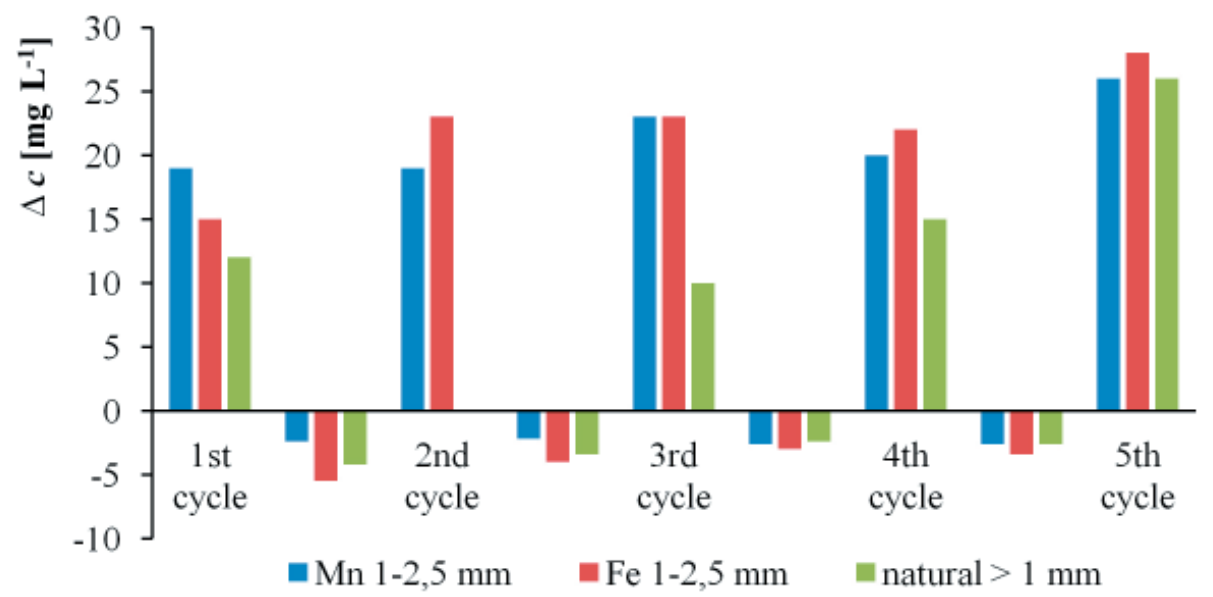

Fig. 16. Change of TOC concentration in five cycles of adsorption followed by regeneration with $\mathrm{O}_{3}$. 
organic pollution. However, further experimental research is needed to verify this hypothesis, including more detailed monitoring of the emerging oxidation intermediates and products.

Natural zeolite caused an increase in the phosphorus concentration in wastewater in the first two adsorption cycles (Fig. 14) probably due to washing-out/desorption from the zeolite. However, from the third cycle on, a significant increase in the adsorption efficiency was observed. Increase of the efficiency was also observed for COD (Fig. 15) and partially also for TOC (Fig. 16) adsorption, which can be attributed to continual cleaning of adsorption sites after longer ozonation time.

\section{Conclusions}

All used zeolites showed good adsorption capacities, and while modified zeolites were more efficient, their disadvantage is in their higher price. Fe-modified zeolite was the most efficient in the removal of ammoniacal nitrogen by adsorption, with the highest values of rate constants and the highest adsorption capacity. This zeolite was also more efficient in COD and TOC removal. Phosphate phosphorus removal efficiency using adsorption was relatively low but Mn-modified zeolite was slightly more efficient than the Femodified zeolite. Natural zeolite was not suitable for phosphorus removal. Adsorption kinetics was described using the pseudo-first and pseudosecond order models. The pseudo-first order model fitted the experimental data better than the pseudo-second order one.

Comparing adsorptive ozonation with adsorption alone, it can be concluded that adsorption is more efficient for ammonia nitrogen removal since ozone has no significant impact on the removal efficiency. For COD removal, adsorptive ozonation is slightly more efficient but from the economical point of view, adsorption is preferable.

Regeneration of zeolites by ozone has to be further examined. The results obtained show that the ammoniacal nitrogen removal efficiency decreased by approximately $18 \%$ after five adsorption cycles, which means that ozone did not completely recover the adsorption capacity of zeolites. On the other hand, for phosphate phosphorus, COD and TOC removal, adsorption efficiency slightly increased in the five cycles, probably due to adsorption sites cleaning after a longer ozonation time. It seems that regeneration of zeolites by ozone is a possible method, but the mechanism has to be clarified and different ozonation times and number of adsorption cycles have to be tested.

\section{Acknowledgements}

This study was supported by the Agency for Research and Development under the contract APVV-0656-12. We also wish to thank the company ZEOCEM, a.s., Slovakia, which has provided zeolites for the experiments.
Abbreviations
COD chemical oxygen demand
$\mathrm{N}-\mathrm{NH}_{4}$ ammonium nitrogen
$\mathrm{N}_{\text {tot }} \quad$ total nitrogen
$\mathrm{P}_{-} \mathrm{PO}_{4}$ phosphate phosphorus
TOC total organic carbon

\section{References}

Bleam W (2017) Surface Chemistry and Adsorption. Soil and Environmental Chemistry. Elsevier: 385-443.

Bowman BT (1982) Conversion of Freundlich Adsorption $\mathrm{K}$ Values to the Mole Fraction Format and the Use of SY Values to Express Relative Adsorption of Pesticides. Soil Science Society of America Journal 46(4): 740-743.

Crawford CB, Quinn B (2017) The interactions of microplastics and chemical pollutants. Microplastic Pollutants. Elsevier: 131-157.

Das B, Mondal NK, Bhaumik R, Roy P (2014) Insight into adsorption equilibrium, kinetics and thermodynamics of lead onto alluvial soil. J. Environ. Sci. Technol 11(4): 1101-1114.

Földesová M, Hudec P, Dillinger P (2006) Study of natural sorbent surfaces by physical nitrogen adsorption [In Slovak]. Bratislava: FCHPT STU: 27-32.

Fontanier V, Farines V, Albert J, Baig S, Molinier J (2006) Study of catalyzed ozonation for advanced treatment of pulp and paper mill effluents. Wat. Res. 40, 303-310.

Foo KY, Hamed BH (2010) Insight into modeling of adsorption isotherm systems. Chemical Engineering Journal 156: 2-10.

Fujita H, Izumi Y, Sagehashi M, Fuji T, Sakoda A (2004) Adsorption and decomposition of water-dissolved ozone on high silica zeolites. Water Research 38: 159-165.

Ho YS, McKay G (1999) Pseudo-second order model for sorption processes. Process Biochemistry 34(5): $451-465$.

Horáková M et al. (2003) Analytika vody. Vysoká škola chemicko-technologická v Praze.

Ishii H, Matsuzawa H, Kobayashi M, Kato M (1978) Method for regenerating an oxidation catalyst. Mitsubishi Rayon Co., Ltd. Japan.

Li D, Yan J, Liu Z (2016) Adsorption kinetic studies for removal of methylene blue using activated carbon prepared from sugar beet pulp. Int. J. Environ. Sci. Technol. 13: 1815-1822.

Lin J, Wang L (2009) Comparison between linear and non-linear forms of pseudo-first-order and pseudo-second-order adsorption kinetic models for the removal of methylene blue by activated carbon. Frontiers of Environmental Science \& Engineering in China 3(3): 320-324.

Melicher M (2013) Removal of toxic and resistant substances using ozone [In Slovak]. Dissertation thesis, Bratislava: Faculty of chemical and food technology, STU. 
Nagy B, Andrada Maicaneanu A, Indolean C, Silvia Burca S, Silaghi-Dumitrescu L, Majdik C (2013) Cadmium (II) Ions Removal from Aqueous Solutions Using Romanian Untreated fir Tree Sawdust - a Green Biosorbent. Acta Chim. Slov. 60 (2): 263-273.

Naushad M, Alothman ZA, Awual MR, Alfadul SM, Ahamad T (2016) Adsorption of rose Bengal dye from aqueous solution by amberlite Ira-938 resin: kinetics, isotherms, and Thermodynamic studies. Desalination and water treatment 57: 13527-13533.

Nethaji S, Sivasamy A, Mandal AB (2013) Adsorption isotherms, kinetics and mechanism for the adsorption of cationic and anionic dyes onto carbonaceous particles prepared from Juglans regia shell biomass. International Journal of Environmental Science and Technology 10 (2): 231-242.

Pitter P (2015) Hydrochemie. $5^{\text {th }}$ edition. VŠCHT Praha.

Plazinski W, Dziuba J, Rudzinski W (2013) Modeling of sorption kinetics: the pseudo-second-order equation and the sorbate intraparticle diffusivity. Adsorption 19(5): 1055-1064.

Qu X, Zheng J, Zhang Y (2007) Catalytic ozonation of phenolic wastewater with activated carbon fiber in a fluid bed reactor. J. Colloid Interface Sci. 390: 429-434.

Reháková M et al. (2003) Utilization of natural zeolite - type clinoptilolite in agrochemistry and agriculture: research report $[$ In Slovak $]$. Košice: Department of inorganic chemistry, University of PJ Šafárik: 260-264.

Ruffino B, Zanetti MC (2011) Bicarbonate and Ammonia Depletion in Ozonized Systems with Bromide Ion, Ozone: Science \& Engineering 33 (6): 425-433.
Ruffino B, Zanetti MC (2012) Experimental study on the abatement of ammonia and organic carbon with ozone. Desalination and Water Treatment 37: 130-138.

Shahbazi A, Gonzalez-Olmos R, Kopinke FD, Pezhman Zarabadi-Poor P, Georgi A (2014) Natural and synthetic zeolites in adsorption/oxidation processes to remove surfactant molecules from water. Separation and Purification Technology 127: 1-9.

Simonin JP (2016) On the comparison of pseudofirst-order and pseudo-second-order rate laws in the modeling of adsorption kinetics. Chemical Engineering Journal 300: 254-263.

Tan KL, Hameed BH (2017) Insight into adsorption kinetics models for the removal of contaminants from aqueous solutions. Journal of the Taiwan Institute of Chemical Engineers 74: 25-48.

Tsai T, Sagehashi M, Fuji T, Sakoda A (2005) Adsorptive Ozonation of Organic Pollutants in Zeolite Monolith: a Kinetic Study. In: Proceedings of 2005 AIChE Annual Meeting: Environmental Division: Environmental Applications of Adsorption.

Valdés H, Zaror CA (2006) Ozonation of benzothiazole saturated-activated carbons: Influence of carbon chemical surface properties. J. Hazard. Mater. B137: 1042-1048.

Wang S, Peng Y (2010) Natural zeolites as effective adsorbents in water and wastewater treatment. Chemical Engineering Journal 156-1: 11-24.

Zhang, Y, Mancke, RG, Sabelfeld, M, Geißen, SU (2014) Adsorption of trichlorophenol on zeolite and adsorbent regeneration with ozone. Journal of Hazardous Materials 271: 178-184. 